\title{
Quantification of Discontinuities in Welded Joints Using Gamma Tomography
}

\author{
Rodrigo Nogueira Palha ${ }^{a}$, Paternak Souza Barros ${ }^{a}$, Yogendra Prasad Yadava ${ }^{a}$, Carlos Costa Dantas ${ }^{b}$, \\ Ricardo Artur Sanguinetti Ferreira ${ }^{a} \mathbb{C}^{*}$ * \\ ${ }^{a}$ Departamento de Engenharia Mecânica, Universidade Federal de Pernambuco, Recife, PE, Brasil \\ ${ }^{b}$ Departamento de Energia Nuclear, Universidade Federal de Pernambuco, Recife, PE, Brasil
}

Received: April 03, 2019; Revised: October 07, 2019; Accepted: October 16, 2019

Gamma tomography was used in this work to evaluate the recurrent defects in welding processes in naval steel sheets. It was used a first-generation equipment consisting of a source of Cesium-137, with activity of the order of $200 \mathrm{mCi}$, coupled to a Thallium-doped Sodium Iodide detector, NaI (Tl). For the study, specimens were produced in ASTM A131-AH36 steel sheets with $13.7 \mathrm{~mm}$ thickness; all welded by Metal Active Gas process. One reference sample was fabricated, with no macroscopically measurable defects and another welded under wind conditions producing a weld bead with different types of discontinuities. The microstructural characterization of welded joints made possible a qualitative evaluation between defective joints, in relation to the joint without defects. With the data of the tomography, 3D graphics were drawn that enabled the statistical survey and analysis of clusters of the results that allowed the localization and the dimensioning of the discontinuities that appeared as counting peaks in these graphics. It was revealed that the defective welding showed porosity of up to $39.28 \%$ of its volume, and the acceptable size crack must be less than $1 \mathrm{~mm}$ based on ASME-B31.3, showing the viability of the tomography for this type of nondestructive analysis.

Keywords: Gamma tomography, discontinuities in welded joints, non-destructive testing.

\section{Introduction}

The joining of metallic materials has been usually accomplished by an electric arc welding process which uses heat source to melt the base metals and addition, forming a melt pool which must be protected by an inert or active gas ${ }^{1}$. In order to assure the quality of the welded structures it is necessary to investigate the integrity of the joint that can be made several methods of Non-Destructive Testing (NDT). The computerized tomography (CT) gamma radiation is one of these methods that lends itself to analyze the attenuation suffered by a beam of radiation in relation to the volume of the object under analysis, allowing the acquisition of data according to the spatial density distribution ${ }^{2}$. Recently, Oliveira et al. ${ }^{3}$ used gamma tomography to analyze weld defects in tubes of API 5L X80 steel.

In this study, computed tomography was used to calculate the porosity in metals, with similar methodology to that used by Pires et al. ${ }^{4}$ to analyze porosity in rocks. After the adequate adaptations for irradiation in flat plates the discontinuities of a welded joint of naval plates could be investigated. Microstructural characterization (destructive test) was associated for ratification of gamma-tomography (non-destructive test) results.

*e-mail: ricardo.sanguinetti@pq.cnpq.br
Due to the nature of the gamma transmission when crossing a material, Figure 1, the intensity of the radiation undergoes an exponential fall described by the Beer-Lambert relation ${ }^{5}$, Equation 1:

$$
I=I_{0} e^{-\mu x}
$$

In equation (1), $\boldsymbol{I}$ is the final intensity of the radiation which arrived in detector, $\boldsymbol{I}_{\boldsymbol{\theta}}$ the initial intensity of the radiation, $\mu$ the linear attenuation coefficient and $\boldsymbol{x}$ is the thickness of the material. The linear attenuation coefficient $\left(\mathrm{cm}^{-1}\right)$ is specific to each material. Often, the term $\mu$ is replaced by $\mu_{m} \rho$,

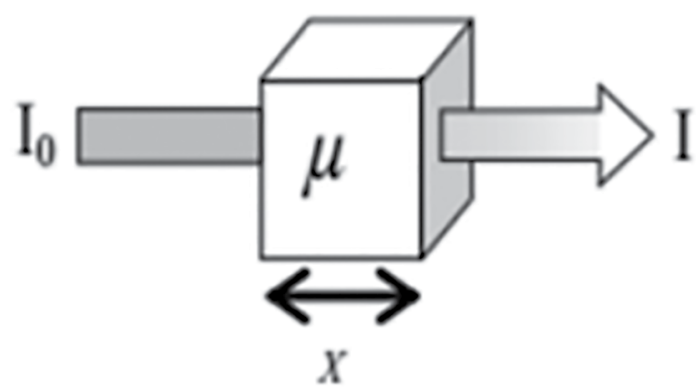

Figure 1. Schematic drawing of radiation attenuation with matter. (OLIVEIRA, 2011). 
where $\mu_{\mathrm{m}}$ is the mass attenuation coefficient $\left(\mathrm{cm}^{2} / \mathrm{g}\right)$ and $\boldsymbol{\rho}$ is the density $\left(\mathrm{g} / \mathrm{cm}^{3}\right)$. The mass attenuation coefficient is independent of physical state ${ }^{6}$.

\section{Materials and Methods}

The study material was ASTM A-131 AH 36 Steel plates with $13.7 \mathrm{~mm}$ thick. From this material, test sheets measuring $100 \times 300 \mathrm{~mm}$ were machined, two by two, with a bevel angle of 25 degrees in each of them. Then, the plates were welded by the MAG process, using AWS ER70S- 6 wire with $\boldsymbol{\varphi}=$ $1,2 \mathrm{~mm}$ and the $\mathrm{Ar}-25 \% \mathrm{CO}_{2}$ protection gas as consumables. Table 1 shows the parameters used for welding.

The welding process was semi-automatically performed with constant speed in all passes, where a motorized system was used to move the torch with specified speed. The plates were made differently, so that a comparative study on the quality of the weld could be made. A test plate was welded while respecting all the cited parameters, so as not to produce any discontinuity macroscopically measurable. In the other test plates, the discontinuities were purposely induced by failures in the shielding gas caused by the use of winds blown transversely to the weld bead.

\subsection{Microstructure characterization}

For microstructural characterization, the test plates were cut into small specimens to be subjected to traditional metallography: cutting, sanding, polishing and etching. A microstructural evaluation of these specimens was made to allow a comparison between the reference plate and the defective plate, considering the discontinuities found in it.

\subsection{Gamma tomography essays}

Gamma tomography (source of Cesium-137) was performed with the plate fixed in the holder and submitted to an activity of the order of $200 \mathrm{mCi}$. Gamma rays emitted energy of $0.662 \mathrm{MeV}$ which, after being collimated $(5.5 \mathrm{~mm}$ aperture) and attenuated by the material, reached a Thalliumdoped Sodium Iodide NaI (TI) detector. The source / detector distance was $33.9 \mathrm{~cm}$. Scanning of the welded region was done in 99 steps of $1 \mathrm{~mm}$ each, with $10 \mathrm{~s}$ counting for each step. After each horizontal scan, the table height was raised $3 \mathrm{~mm}$ for further scanning.

Table 1. Welding parameters used in experiments.

\begin{tabular}{lc}
\hline \multicolumn{1}{c}{ Welding Parameters } \\
\hline Voltage (V) & 22 \\
Current (A) & 140 \\
Gas flow rate (1/min) & 18 \\
Vel. Wire (m/min) & 6 \\
Vel. Torch (mm/min) & 6 \\
Stick out (mm) & 8 \\
\hline
\end{tabular}

For the calculation of radiometric density $\rho_{\mathrm{m}}$, Equation $2^{7}$ based on the Beer-Lambert relationship was used ${ }^{8}$. This equation (2) is a function of the values of the mass attenuation coefficient $\mu_{m}$ of the base metal and weld metal, the diameter or thickness of the plate $\boldsymbol{D}$ and the logarithmic ratio between the empty tube intensities $\boldsymbol{I}_{v}$ and of the whole with flow $\boldsymbol{I}_{\boldsymbol{f}}$, respectively. This equation can be used by replacing $\boldsymbol{I}_{v}$ by $\boldsymbol{I}_{\boldsymbol{o}}$ and $\boldsymbol{I}_{\boldsymbol{f}}$ by $\boldsymbol{I}$ referring to Equation 1.

$$
\rho_{m}=\frac{1}{\mu_{m} D} \ln \frac{I_{\mathrm{v}}}{I_{\mathrm{f}}}
$$

Using equation (2), the mass linear attenuation coefficient for the base metal $\left(\mu_{\mathrm{m}}=0.0742\right)$ and for the weld metal $\left(\mu_{m}=\right.$ 0.0733 ) were obtained. These results are in accordance with the NIST XCOM ${ }^{9}$. The gravimetric density was calculated by Equation 3:

$$
\rho=\frac{m}{V}
$$

In equation (3), $\boldsymbol{\rho}$ is the gravimetric density, $\boldsymbol{m}$ the mass and $\boldsymbol{V}$ the volume. Samples with parallelepiped-shaped were produced by machining with edges aligned by a milling machine to ensure the scanning the edges of the volume.

For sample volume measurements, a micrometer with a sensitivity of $0.001 \mathrm{~mm}$ was used. The volumes were then weighed using an analytical precision balance, with a capacity of $220 \mathrm{~g}$ and a precision of $0.1 \mathrm{mg}$. Using these values, the gravimetric density $\boldsymbol{\rho}$ of each sample was calculated. With the CT scanner was made reading the $\boldsymbol{I}_{o}$, which is the radiation level measured without the specimen. For this, ten measurements with a duration of 10 seconds each were performed and then an average of the values taken.

Based on the results of density values and attenuation coefficients, the irradiated volume were calculed. The volume of the radiation beam that passes through the material and reaches the detector is cylindrical in shape with a diameter of $5.5 \mathrm{~mm}$. In this way, the volume $\boldsymbol{V}$ of the material traversed by the beam of radius $\boldsymbol{r}$ in a thickness $\boldsymbol{l}$ was calculated by Equation 4.

$$
\mathrm{V}=\pi r^{2} l
$$

The region affected by the gamma radiation beam had a constant radius of $2.75 \mathrm{~mm}$, generating an irradiated area of $0.091415 \mathrm{~mm}^{2}$. The value of $h$ refers to the irradiated depth, at each scanning step was calculated by Equation 5, based on the Beer-Lambert criterion.

$$
h=\frac{1}{\mu} \ln \left(\frac{I O}{I}\right)
$$


A defect (discontinuity) represents an empty space resulting from the lack of material that is not filled by the weld. Considering the smaller attenuation of the beam, it can be considered that the irradiated effective volume would be equivalently smaller than the physical volume of the sample without defects as shown in Figure 2.

This method closely approximates the work described by Schon ${ }^{10}$ to calculate the percentage of porosity in rocks. The percentage of porosity $\varphi$, given as a function of the relationship between pore volume $v_{p}$ and total volume $v_{t}$, can be calculated by equation (6).

$$
\phi=\left(\frac{v_{p}}{v_{t}}\right) \cdot 100
$$

However, by the method using gamma transmission, it is possible to estimate the porosity by relating the density value of the sample ${ }^{4}$, according to Equation (7):

$$
\phi=\left(1-\frac{\rho_{m}}{\rho}\right) .100
$$

In equation (7), $\boldsymbol{\rho}_{m}$ is the radiometric density of the gamma transmission of the material, obtained by Equation (2), $\rho$ the density of the material used in the experiment provided by the literature, such as NIST $\mathrm{XCOM}^{7}$. The gravimetric density $\boldsymbol{\rho}$ can also be calculated by Equation (3).

\section{Results and Discussions}

\subsection{Reference sheet}

The high quality of the reference weld can be seen from the microscopic images shown in figure 3. No pores, cracks or any discontinuities were found in its structure. It is demonstrated that this weld served perfectly as reference

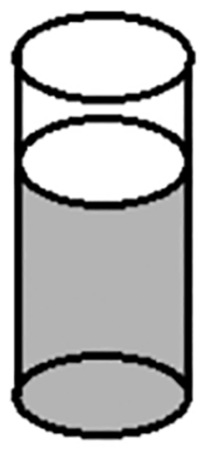

A

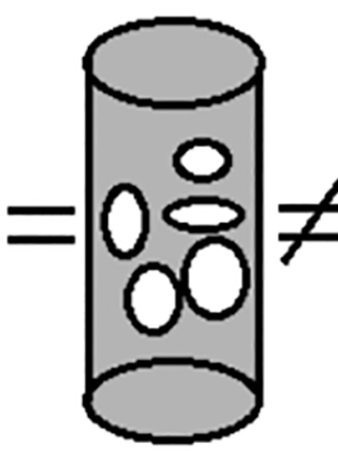

B

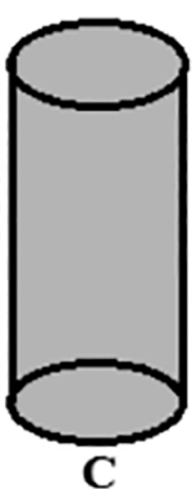

C
Figure 2. In the diagram is shown in $\mathrm{A}$ and $\mathrm{B}$ equivalet volumes (equivalent defects) crossed by a gamma beam. In $\mathrm{C}$, a traversed volume without defects. in this work. In Figure 3A it is observed a pass of the weld bead indicated by the red arrow and no existing defect.

Figure 3B shows the root pass of the weld, where the effect of epitaxy on the columnar growth of the grains in the molten region is seen, without any apparent discontinuity. Figure 3C shows the three zones of the weld joint: base metal (BM), heat-affected zone (HAZ) and weld metal (WM). Due to the microstructure of the three adjacent regions, the weld quality is evidenced.

As expected, the microscopic images of welded joints with failures in the shielding gas showed large pores, cracks and lack of fusion. The absence of the shielding gas besides destabilizing the electric arc, produces a great oxidation of the joint, contributing to the formation of cracks and large pores. Studying the effects of wind on welding with tubular wire in shipyards located in the brazilian northeast, Lessa et al. ${ }^{11}$ obtained equivalent results.. Figure 4 shows cracks with diameters ranging from $22.01 \mu \mathrm{m}$ to $34.46 \mu \mathrm{m}$ in thickness and pores with diameters ranging from 1608.54 $\mu \mathrm{m}$ to $2114.50 \mu \mathrm{m}$.

In Figure 5 it is possible to observe pores with 25,94 $\mu \mathrm{m}$ and up to $561,83 \mu \mathrm{m}$ of diameter. A long crack with an average thickness of $4.92 \mu \mathrm{m}$ was also found.

Based on the data obtained with the gamma tomography of the plates, 3D graphics were created, as shown in figures 6 and 7. These graphs show the existence or not of defects in a welded joint. These defects are characterized by high counting peaks. This type of signal (high peaks) indicates a lot of porosity and other types of discontinuities that caused less attenuation in the gamma beam due to lack of material in the weld. A greater number of defects implies a lower attenuation of the gamma beam, increasing the gamma particle count that reaches the detector.

The 3D graph, obtained from the computed tomography of the reference weld, revealed that there are no measurable discontinuities capable of altering the attenuation of the gamma beam, both on the weld bead and on the base metal (Figure 6). All the irradiated surface, base metal and weld metal, presented peaks of equivalent height, characterizing the good quality of the welding, as already evidenced by metallography, where there are no detectable defects in this sample, ensuring compliance with ASME-B31.3 standard for tomography.

The 3D graph obtained from the computed tomography in the weld with fault of the protection gas (Figure 7) revealed peaks that reached 8738 counts in a region on the weld bead, the regions between 0 to 2 and between 6 to 8 corresponding the HAZ. These high points characteristic of the presence of discontinuities (absence of material) revealed an effective reduction in weld bead thickness.

Based on the attenuation of the gamma beam, the effective thickness of the defective weld bead was measured by three scans straight S1, S2 and S3, as shown schematically in Figure 8 . 

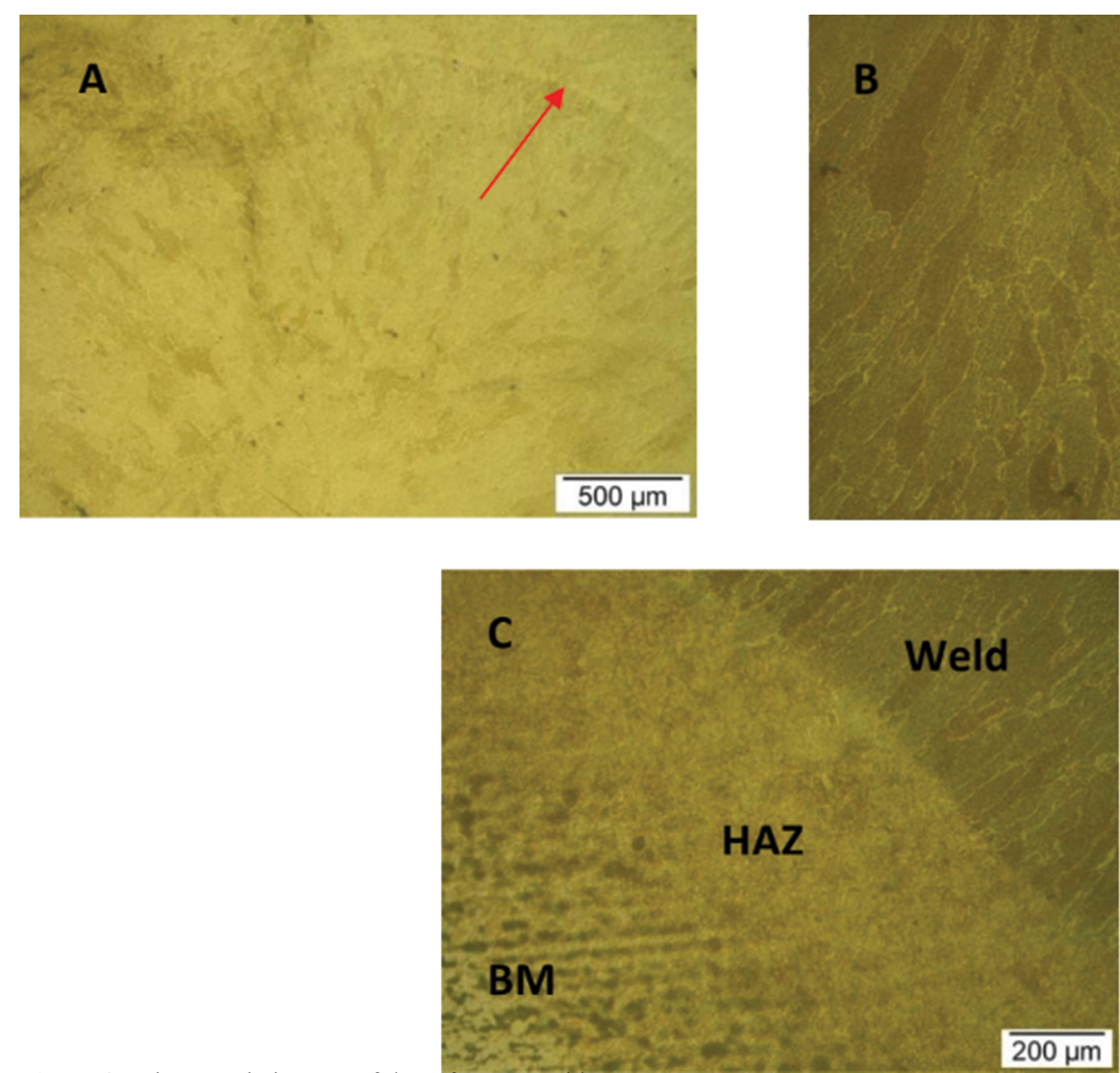

Figure 3. Microscopic images of the reference weld.
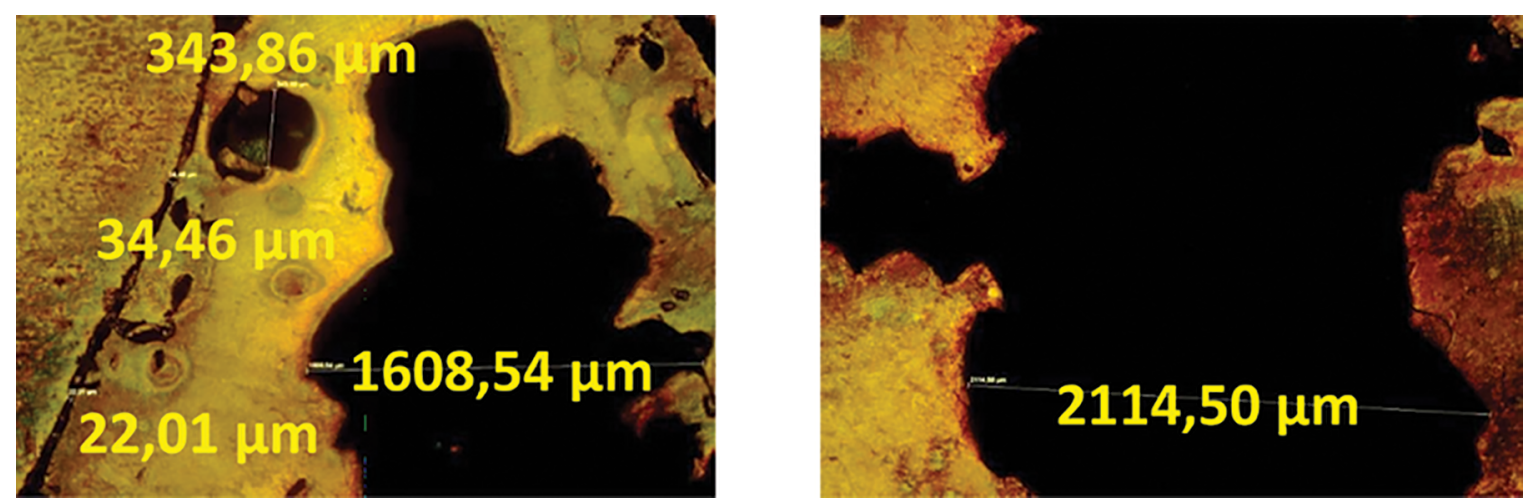

Figure 4. Microscopy showing cracks and region without material filling.

The average thickness measured along the $\mathrm{S} 1$ scan was $1.066 \mathrm{~cm} \pm 0.049 \mathrm{~cm}$, in the $\mathrm{S} 2$ scan was $1.018 \mathrm{~cm} \pm 0.063$ $\mathrm{cm}$ and in the $\mathrm{S} 3$ scan was $1.301 \mathrm{~cm} \pm 0.037 \mathrm{~cm}$. These results showed an average error of $17.58 \%$, in relation to the nominal thickness of the sheet, which was $1.37 \mathrm{~cm}$ (Figure 8).

Thickness below $1.29 \mathrm{~cm}$ is an indication of the presence of defects. On defective weld bead, the effective thickness reached $0.817 \mathrm{~cm}$. Based on this result, we can admit the existence of a large number of discontinuities (cracks, bubbles and pores) throughout this weld bead, even without the visualization of the internal part that was only ratified after the metallographic tests. This variation of thickness associated with the presence of discontinuities (defects) can also be observed on surfaces with sharp curvature, as reported by Moura et al. ${ }^{5}$ when applying gamma radiation in small tubes

The results of the porosity $\varphi$ were obtained by calculation according to Pires ${ }^{4}$ through Equation 7. For the base metal, the result of the porosity $\varphi$ was $0.053 \%$ considering the reference density and, considering the gravimetric density (Equation 3 ), the porosity $\varphi$ was $0.068 \%$.

For the region of the reference solder, the porosity $\varphi$ calculated by the method used by Pires ${ }^{4}$ was $0.177 \%$, considering the reference density and $0.192 \%$, considering the gravimetric density. 


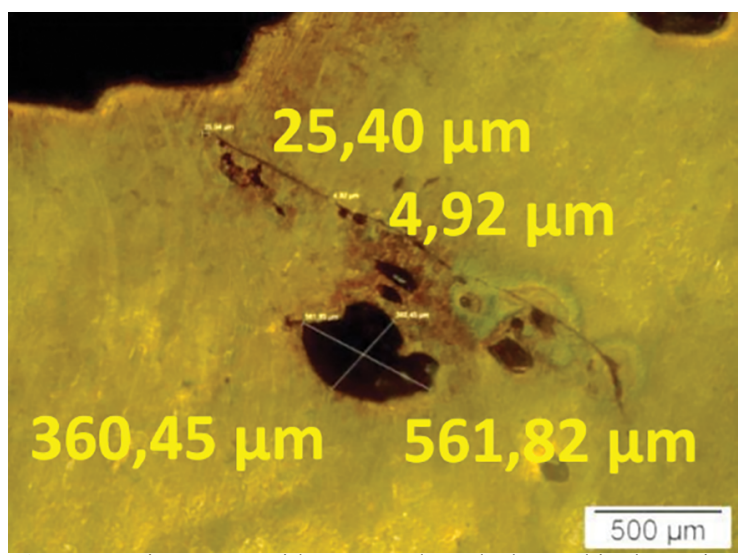

Figure 5. Microscopy with pores and cracks located in the region of the weld.

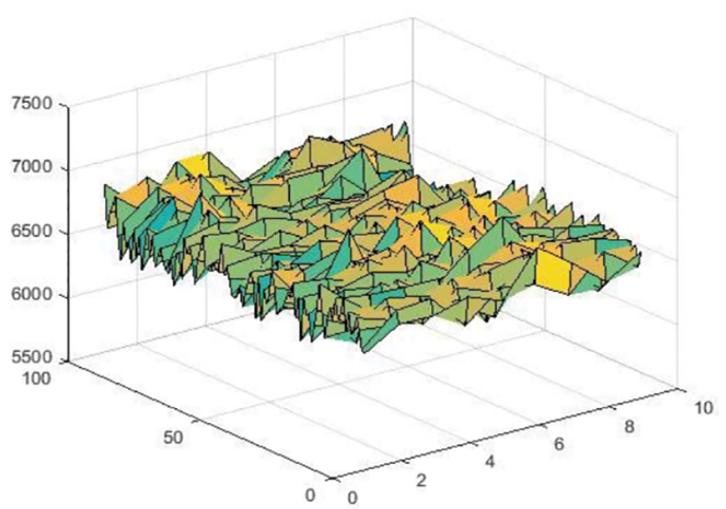

Figura 6. Gráfico 3D da tomografia da chapa com a solda de referência.

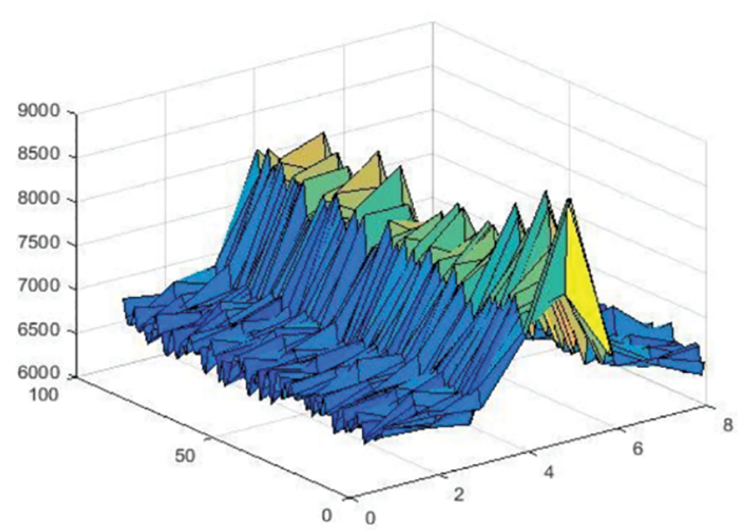

Figura 7. Gráfico 3D da tomografia da chapa soldada com falhas do gás de proteção.

In the test plate with defective bead, where regions with material thickness of $0.817 \mathrm{~cm}$ were found, the porosity $\varphi$ measured by the method of Pires ${ }^{4}$ using the reference density was $39.28 \%$. In this same sample, considering the gravimetric density, the porosity $\varphi$ calculated with Equation 3 was $37.21 \%$.

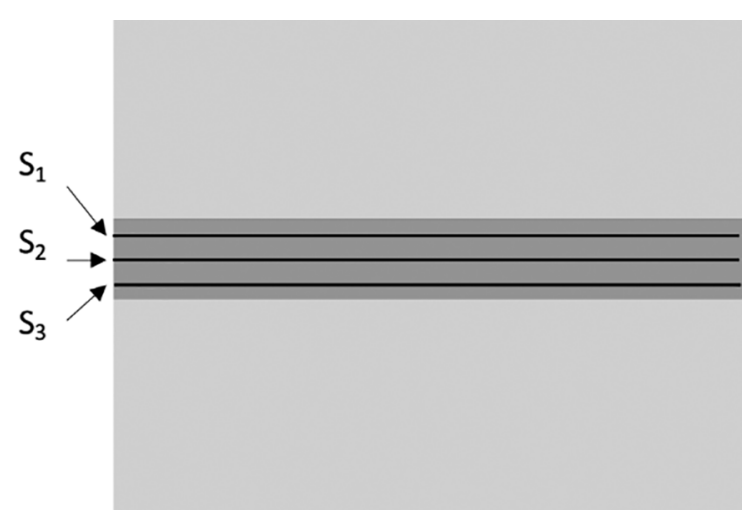

Figure 8. Test plates and the positioning of the three scans, S1, $\mathrm{S} 2$ and $\mathrm{S} 3$.

\section{Conclusion}

The results showed the potential of computerized tomography for inspection of defects in welded joints. From the results obtained, it was possible to observe a satisfactory response of the tomographic signal, comparing a reference solder with a solder with discontinuities.

The presence of discontinuity in a welded joint decreases its effective volume, reflected in a lower attenuation of the gamma beam, when crossing the sample. In this way, the detector is hit by a larger volume of gamma particles, generating high peaks in the 3D diagrams.

In the tomograph, the volume reduction is measured from the effective thickness reduction. In the reference weld the average value of the effective thickness of weld beam was $1.128 \mathrm{~cm}$. In the defective weld, the effective thickness of weld beam reached $0.817 \mathrm{~cm}$. Considering that the thickness of the sheet was $1.37 \mathrm{~cm}$, the reductions of the effective thickness in the weld without and with defect were of $17.66 \%$ and $40.36 \%$, respectively.

The porosity measured on the basis of the reference and gravimetric densities were respectively: $0.051 \%$ and $0.066 \%$ for the base metal; $0.177 \%$ and $0.192 \%$ for the weld bead without defect and $39.28 \%$ and $37.21 \%$ for the defective weld bead.

\section{Referências}

1. Wainer E, Brandí SD, Melo FDH. Soldagem: Processos e Metalurgia. $1^{\mathrm{a}}$ ed. São Paulo (SP): Edgard Blücher; 2004.

2. Kumar SB, Moslemian D, Dudukovic MP. Gas-holdup measurements in bubble columns using computed tomography. AIChE Journal. 1997;43(6):1414-1425.

3. Oliveira KM, Dantas CC, Ferreira RAS, Melo SB, Lima EA, Barbosa ES. Gamma ray CT and MCNPX simulation applied to weld structure investigation. In: Anais do $8^{\circ}$ World Congress on Industrial Process Tomography (WCIPT8); 2016 set. 26-29; Foz do Iguaçu (PR), Brasil. Foz do Iguaçu (PR): WCIPT8; 2016. v. 1. 
4. Pires LF. Gamma-ray computed tomography to characterize soil surface sealing. Applied Radiation and Isotopes. 2002;57(3):375380 .

5. Moura AE, Dantas CC, Nery MS, Barbosa JM, Rolim TL, Lima EAO, et al. Non-destructive evaluation of weld discontinuity in steel tubes by gamma ray CT. Nuclear Instruments and Methods in Physics Research: B. 2015;349:155-162.

6. Salvador PAV. Análise de sistemas multifásicos utilizando tomografia computadorizada gama monoenergética e polienergética [tese]. São Paulo: Instituto De Pesquisas Energéticas e Nucleares (USP); 2008.

7. Bartolomew RN, Casagrande RM. Measuring solids concentration in fluidized systems by gamma-ray absorption. Industrial and Engineering Chemistry. 1957;49(3):428-431.
8. Dantas CC, Melo SB, Oliveira EF, Simões FPM, Santos MDG, Santos VA. Measurement of density distribution of a cracking catalyst in experimental riser with a sampling procedure for gamma ray tomography. Nuclear Instruments and Methods in Physics Research: B. 2008;266(5):841-848.

9. National Institute of Standards and Technology (NIST). XCOM - Element/Compound/Mixture Selection. Gaithersburg, USA: NIST; [acesso em 2017 fev 18]. Disponível em: http://physics. nist.gov/PhysRefData/Xcom/html/xcom1-t.html

10. Schon J. Propriedades físicas das rochas aplicadas à engenharia: fundamentos teóricos e práticos. 1a ed. Rio de Janeiro: Elsevier; 2015.

11. Lessa RMA, Yadava YP, Gama JLL, Ferreira RAS. Mechanical properties of welding joints of ah 36 steel processed under different wind actions [CD-ROM]. In: 21st Brazilian Congress of Mechanical Engineering; 2011 out. 24-28; Natal (RN), Brasil. Proceedings of COBEM, 2011. Rio de Janeiro (RJ): ABCM; 2011. p. 1-10. 